\title{
Degradation of Aqueous Paraquat by Surface Air Plasma: A Kinetic Study
}

\author{
Camilo Fabris, ${ }^{a}$ Gabriele B. Baroncello ${ }^{a}$ and Péricles I. Khalaf $*, a$ \\ ${ }^{a}$ Departamento de Química, Universidade Tecnológica Federal do Paraná, 85503-390 Pato Branco-PR, Brazil
}

\begin{abstract}
In this work, the kinetics of aqueous paraquat (PQ) degradation in a surface air plasma reactor was studied under a variety of experimental conditions. Additionally, stable reactive oxygen species (ROS) and reactive nitrogen species (RNS) were determined. PQ degradation followed pseudo-second order kinetics, increasing both observed rate constant $\left(\mathrm{k}_{\mathrm{obs}}\right)$ and removal efficiency by increasing the temperature. Increasing PQ concentration decreased $\mathrm{k}_{\mathrm{obs}}$, as a constant amount of reactive species is generated at the same conditions. Both the decrease of the entropy of activation $\left(-157.1 \mathrm{~J} \mathrm{~K}^{-1} \mathrm{~mol}^{-1}\right)$ and the low value of the enthalpy of activation $\left(+9.9 \mathrm{~kJ} \mathrm{~mol}^{-1}\right)$ supported a bimolecular associative mechanism for producing the transition state. From the ionic strength effect, the transition state is formed by two ions of opposite charges $\left(\mathrm{z}_{\mathrm{A}} \mathrm{z}_{\mathrm{B}}=-3.6\right)$. Produced RNS (nitrous and nitric acid) followed zero-order kinetics. Gaseous ozone was the only ROS identified, as hydrogen peroxide concentration was below the limit of detection.
\end{abstract}

Keywords: aqueous paraquat degradation, surface air plasma, transition state

\section{Introduction}

Paraquat (PQ, Figure 1) is a bipyridylium herbicide and its International Union of Pure and Applied Chemistry (IUPAC) name is 1,1-dimethyl-4,4-bipyridiniumdichloride. It is a white crystalline powder and its chemical structure has mainly an ionic character, completely dissociated in water and moderately or slightly soluble in organic solvents, but insoluble in oil and fat. It is odorless, non-volatile, hygroscopic, non-flammable and, depending on purity, its melting point may vary from 175 to $180^{\circ} \mathrm{C}$, with thermal decomposition starting from $345^{\circ} \mathrm{C}$. ${ }^{1}$

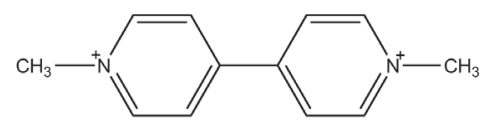

$2 \mathrm{Cl}^{-} \cdot \mathrm{xH}_{2} \mathrm{O}$

Figure 1. Schematic structure of paraquat (1,1-dimethyl4,4-bipyridiniumdichloride).

Due to its high acute toxicity, the greatest among the herbicides on the market, combined with the highest mortality rate, also attributed to the lack of an antidote for a poisoning treatment, PQ is the deadliest herbicide commercialized nowadays, which generates discussions about its application. Its acute toxicity, based on the median lethal dose $\left(\mathrm{LD}_{50}\right)$, shows that PQ is 28 times more toxic

*e-mail: pericles@utfpr.edu.br than glyphosate, which is the most used herbicide. ${ }^{2}$ For these reasons this herbicide is now forbidden in Europe, although its use has continued in other continents, and therefore the paraquat quantity in water has grown. A great concern also exists related to the possibility of its presence in water, particularly drinking water, for instance, due to a deliberate contamination event. ${ }^{3,4}$

Because of PQ's high water solubility and its acute toxicity, it is important to evaluate an efficient method for its degradation in aqueous media. ${ }^{5}$ In the literature, most studies report the use of advanced oxidation process (AOP), not only referring to photocatalytic processes by the action of $\mathrm{TiO}_{2}$ and/or Fenton's reagents, ${ }^{4-7}$ but also electrochemical advanced oxidation, ${ }^{8}$ and catalytic wet peroxide oxidation ${ }^{9}$ to degrade PQ. However, just a few studies are concerned with PQ degradation kinetics, as summarized on Table 1. In order to compare these results, their half-lives are also shown in Table 1, in which all degradations followed pseudo-first order kinetics.

Recently, plasma processes for degradation of organic species in aqueous solution, such as methylene blue, ${ }^{13,14}$ phenol, ${ }^{15}$ amoxicillin and doxycycline, ${ }^{16}$ have also been conducted for water treatment. The advantages of the plasma treatment lie on the economical and practical aspects, since reactants commonly used on AOPs (such as ozone $\left(\mathrm{O}_{3}\right)$ and/or hydrogen peroxide $\left(\mathrm{H}_{2} \mathrm{O}_{2}\right)$ ) and other highly oxidant species are produced in situ by the plasma discharge. As a result, less effort is put on adding 
Table 1. Comparison between different treatment methods for PQ degradation involving kinetics studies

\begin{tabular}{|c|c|c|c|}
\hline Treatment & Conditions & Half-life / min & Reference \\
\hline Electrochemical advanced oxidation & $\begin{array}{c}{[\mathrm{PQ}]_{0}=77.8 \mu \mathrm{M}} \\
\mathrm{pH}=3.0 \\
{\left[\mathrm{Fe}^{2+}\right]=0.2 \mathrm{mM}} \\
\mathrm{T}=25 \pm 2^{\circ} \mathrm{C}\end{array}$ & 26.4 & 8 \\
\hline Catalytic wet peroxide oxidation & $\begin{array}{c}{[\mathrm{PQ}]_{0}=77.8 \mu \mathrm{M}} \\
\mathrm{pH}=3.0 \\
{\left[\mathrm{H}_{2} \mathrm{O}_{2}\right]=12.05 \mathrm{mM}} \\
{[\text { activated carbon, catalyst }]=1 \mathrm{~g} \mathrm{~L}^{-1}} \\
\mathrm{~T}=30,40,50,60 \text { and } 70^{\circ} \mathrm{C}\end{array}$ & 27.7 & 9 \\
\hline Photocatalysis under UV irradiation & $\begin{array}{c}{[\mathrm{PQ}]_{0}=38.9 \mu \mathrm{M}} \\
\mathrm{pH}=3.0 \\
\mathrm{TiO}_{2}-\mathrm{SBA}-15=0.5 \mathrm{~g} \mathrm{~L}^{-1} \\
\mathrm{~T}=\text { not mentioned }\end{array}$ & 84.0 & 10 \\
\hline Photocatalysis under UV irradiation & $\begin{array}{c}{[\mathrm{PQ}]_{0}=58.3 \mu \mathrm{M}} \\
\mathrm{pH}=\text { not mentioned } \\
{\left[\mathrm{ZrO}_{2} / \mathrm{TiO}_{2}, 20: 80(\mathrm{~m}: \mathrm{m})\right]=0.4 \mathrm{~g} \mathrm{~L}^{-1}} \\
\mathrm{~T}=\text { not mentioned }\end{array}$ & 123.8 & 11 \\
\hline Photocatalysis under UV irradiation & $\begin{array}{c}{[\mathrm{PQ}]_{0}=388.9 \mu \mathrm{M}} \\
\mathrm{pH}=\text { not informed } \\
{\left[\mathrm{TiO}_{2}\right]=0.1 \mathrm{~g} \mathrm{~L}^{-1}} \\
12 \mathrm{~W} \mathrm{~m}^{-2} \\
\mathrm{~T}=\text { constant, but not informed }\end{array}$ & 784.7 & 12 \\
\hline
\end{tabular}

$[\mathrm{PQ}]_{0}$ : initial paraquat concentration; T: temperature; $\mathrm{TiO}_{2}-\mathrm{SBA}-15$ : Santa Barbara acids (SBA)-15 mesoporous silica coated with $\mathrm{TiO}_{2}$.

or removing reactants such as iron ions (Fenton's reagent) or $\mathrm{TiO}_{2}$ (photocatalyst), that do not need to be employed any longer.

To the best of our knowledge, no other work reports the use of any kind of plasma setup for PQ treatment and, therefore, it is the first time in the literature that aqueous PQ degradation by a plasma system is investigated. In this work, a kinetic study was performed to evaluate PQ degradation by a surface air plasma system. Effects of initial PQ concentration ([PQ $\left.]_{0}\right)$, temperature $(\mathrm{T})$ and ionic strength on the observed rate constant $\left(\mathrm{k}_{\mathrm{obs}}\right)$ were evaluated and the kinetic parameters were calculated in order to determine the transition state (TS). PQ removal efficiency (RE) was calculated to identify the best degradation condition. Moreover, the characterization and chemical kinetic study of the stable reactive oxygen species (ROS) and reactive nitrogen species (RNS) produced by the surface air plasma were conducted.

\section{Experimental}

\section{Surface air plasma system}

The surface air plasma system used for PQ degradation is shown in Figure 2. It consists of a modified version described elsewhere. ${ }^{13,14}$ The plasma reactor is made of glass, with a cooling jacket attached to a circulating thermostatic bath (Microquímica, MQBMP-01) to control and to keep a constant temperature (in a $\pm 0.1{ }^{\circ} \mathrm{C}$ interval) during the degradations. Tungsten electrodes (Energyarc, diameter $(\varnothing)=2.4 \mathrm{~mm}, 2 \% \mathrm{Th}$ ) were supported on polytetrafluoroethylene (PTFE) lids on the upper and bottom parts of the plasma reactor, using a point-plane geometry. The surface air plasma was generated by the potential difference between the electrodes, supplied by a high voltage (HV) transformer (Neon Ena, $8 \mathrm{kV} \mathrm{AC}$, $30 \mathrm{~mA}, 60 \mathrm{~Hz}$ ). The electrode gap was kept constant $(20 \mathrm{~mm})$ in all degradations. For each condition, $100 \mathrm{~mL}$ of PQ solution $\left(\mathrm{pH}_{0}=8.02\right)$ were placed in contact with the bottom electrode and the generated plasma above the aqueous surface was in contact with the treated solution, characterizing a direct treatment. The plasma was produced under atmospheric pressure using the atmospheric air contained in the gas phase of the reactor, aiming to minimize costs, and focusing on environmental applications. A hole was drilled $(\varnothing=2.0 \mathrm{~mm}$ ) in the upper lid, to ensure gas exchange with the atmosphere. Also in the upper lid, a thermometer was supported (to ensure temperature control), and a glass sampling tube $(\varnothing=7.0 \mathrm{~mm})$, both in contact with the aqueous phase of the reactor.

Plasma-treated solution sampling at predetermined time intervals was made by connecting a plastic syringe in the sampling tube. The sampled solutions were then transferred to microtubes (Axygen). The chemical reactions that take place after sampling were quenched by using a $1 \mathrm{M}$ sodium hydroxide $(\mathrm{NaOH})$ solution. 


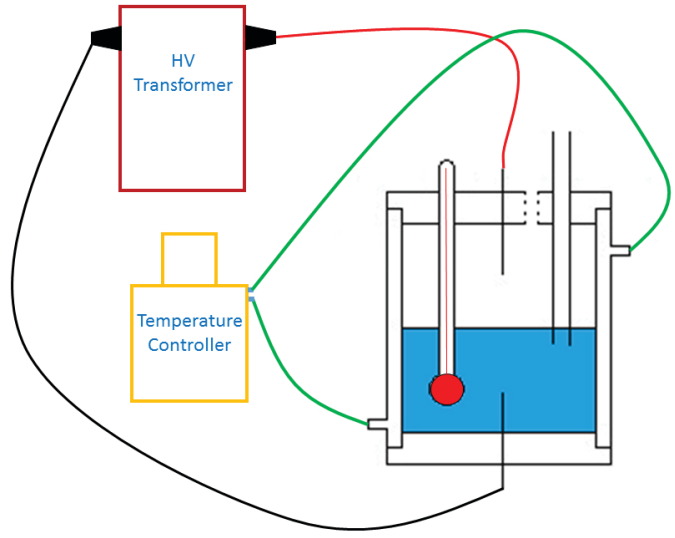

Figure 2. Schematic diagram of the surface air plasma system used for PQ degradation.

\section{Kinetic study of PQ degradation and removal efficiency}

Effects of $\mathrm{T}$ and $[\mathrm{PQ}]_{0}$ during degradations on $\mathrm{k}_{\mathrm{obs}}$ were examined by the univariate method. The effect of temperature was evaluated using $[\mathrm{PQ}]_{0}=10 \mu \mathrm{M}$ and keeping the temperature at 5.0, 15.0, 25.0, 35.0 and $45.0^{\circ} \mathrm{C}$. The maximum temperature of $45.0^{\circ} \mathrm{C}$ was chosen to minimize evaporation of the solvent, which would result in a higher value for the determined concentrations. The effect of $[\mathrm{PQ}]_{0}$ was investigated using $10,15,30$ and $50 \mu \mathrm{M}$, while keeping the temperature at $25.0^{\circ} \mathrm{C}$. Because the flooding method was employed, PQ concentrations must be low, so the concentration of water is kept constant. Treatment time was set to $180 \mathrm{~min}$, for every experimental condition.

Rate constants are generally temperature dependent and most reactions obey the Arrhenius equation (equation 1):

$\mathrm{k}=\mathrm{A} \mathrm{e}^{-\frac{\mathrm{E}_{\mathrm{a}}}{\mathrm{RT}}}$

where $\mathrm{A}$ is the pre-exponential factor, $\mathrm{E}_{\mathrm{a}}$ is the activation energy, $\mathrm{R}$ is the gas constant and $\mathrm{T}$ is the absolute temperature (K). Therefore, the Arrhenius plot, i.e., a plot between $\ln (\mathrm{k})$ vs. 1 / T, should be a straight line with a negative slope, being possible to extract $\mathrm{A}$ from the intercept and $\mathrm{E}_{\mathrm{a}}$ from the slope.

The activation parameters, such as entropy of activation $\left(\Delta \mathrm{S}^{\ddagger}\right)$ and enthalpy of activation $\left(\Delta \mathrm{H}^{\ddagger}\right)$ were extracted on the basis of the logarithmic form of the Eyring equation (equation 2):

$\ln \frac{\mathrm{k}}{\mathrm{T}}=-\frac{\Delta \mathrm{H}^{\ddagger}}{\mathrm{RT}}+\frac{\Delta \mathrm{S}^{\ddagger}}{\mathrm{R}}+\ln \frac{\mathrm{k}_{\mathrm{B}}}{\mathrm{h}}$

where $\mathrm{k}_{\mathrm{B}}$ and $\mathrm{h}$ are the Boltzmann and Planck constants, respectively. By plotting $\ln \left(\mathrm{k}_{\mathrm{obs}} / \mathrm{T}\right)$ as a function of $1 / \mathrm{T}$, it is possible to extract $\Delta \mathrm{H}^{\ddagger}$ from the slope and $\Delta \mathrm{S}^{\ddagger}$ from the intercept.

$\mathrm{RE}$ was calculated as in equation 3 :

$\operatorname{RE}(\%)=\left[1-\frac{\mathrm{A}_{\mathrm{e}}}{\mathrm{A}_{0}}\right] \times 100$

where $\mathrm{A}_{0}$ and $\mathrm{A}_{\mathrm{e}}$ are the $\mathrm{PQ}$ absorbances at the beginning $(t=0)$ and at the end $(t=180 \mathrm{~min})$ of plasma treatment, respectively.

\section{Effect of the ionic strength}

Considering a process in which two ionic species $A$ (with a charge $\mathrm{z}_{\mathrm{A}}$ ) and $\mathrm{B}$ (with a charge $\mathrm{z}_{\mathrm{B}}$ ) must come together to form a transition state:

$\mathrm{A}^{\mathrm{zA}}+\mathrm{B}^{\mathrm{zB}} \rightarrow\left[\mathrm{AB}^{\mathrm{zA}+\mathrm{zB}}\right]^{\text {* }}$

as the reaction involves charged reactants (electrolites), it occurs under non-ideal conditions which is predicted by the Debye-Huckel theory, and the observed rate constant shows a dependence on the ionic strength. This relation is shown in equation 5 for higher values of ionic strengths:

$\log \mathrm{k}_{\text {non-ideal }}=\log \mathrm{k}_{\text {ideal }}+1.02 \mathrm{z}_{\mathrm{A}} \mathrm{z}_{\mathrm{B}} \frac{\sqrt{\mathrm{I}}}{1+\sqrt{\mathrm{I}}}$

where $\mathrm{I}$ is the ionic strength and $\mathrm{k}_{\text {ideal }}$ is the rate constant extrapolated to $\mathrm{I}=0$. The ionic strength is defined as:

$\mathrm{I}=\frac{1}{2} \sum_{\mathrm{i}}\left(\mathrm{c}_{\mathrm{i}} \mathrm{z}_{\mathrm{i}}^{2}\right)$

where $c_{i}$ is the concentration of the ionic species and $z_{i}$ is the charge of the ion.

The ionic strength effect was studied in the range of 0.00163 to $0.21330 \mathrm{M}$ by adding appropriate volumes of an $\mathrm{MgCl}_{2}$ stock solution $(1 \mathrm{M})$. Each experimental data point was repeated 3 times, in order to evaluate the uncertainty of the analysis. For evaluating the ionic strength effect, the temperature was kept constant at $45.0^{\circ} \mathrm{C},[\mathrm{PQ}]_{0}=10 \mu \mathrm{M}$, and the initial and final $\mathrm{pH}$ and conductivity were determined experimentally.

\section{Chemical analysis}

\section{UV-Vis absorption spectroscopy}

A $120 \mu \mathrm{M}$ stock solution was prepared by dissolving the solid PQ (Sigma-Aldrich, 98\%) in a $1 \mathrm{~L}$ volumetric flask using ultrapure water. The more diluted solutions 
were prepared using appropriate volumes of the stock solution. For each condition, $100 \mathrm{~mL}$ of $\mathrm{PQ}$ solution in the appropriate concentration was used.

PQ concentrations were determined spectrophotometrically by its reaction with dehydroascorbic acid (DHA). This method is environmentally friendly, since it uses small reactant quantities and the results have no significant differences in comparison with those indicated by the World Health Organization (WHO) utilizing high performance liquid chromatography (HPLC). Another advantage of the method is that nitrate and nitrite species do not interfere. ${ }^{17}$

All solutions were prepared with analytical grade chemicals and freshly distilled ultrapure water. DHA solution was prepared by dissolving $0.04403 \mathrm{~g}$ of ascorbic acid $\left(\mathrm{C}_{6} \mathrm{H}_{8} \mathrm{O}_{6}\right.$, Sigma-Aldrich, 99\%), $0.17835 \mathrm{~g}$ of potassium iodate $\left(\mathrm{KIO}_{3}\right.$, Sigma-Aldrich, $\left.99.5 \%\right)$ and $0.1861 \mathrm{~g}$ of ethylenediaminetetraacetic acid (EDTA, SigmaAldrich, $99.4 \%$ ) in a $50 \mathrm{~mL}$ volumetric flask.

PQ determination was made by its reaction with DHA in a basic medium, producing a blue PQ free radical that strongly absorbs at $600 \mathrm{~nm}\left(\varepsilon=10300 \mathrm{M}^{-1} \mathrm{~cm}^{-1}\right)$. PQ quantification on the sampled aqueous solutions was made through calibration curves. The linear range for PQ determination in this study was between 0.95 and $66.30 \mu \mathrm{M}$.

The method for $\mathrm{H}_{2} \mathrm{O}_{2}$ determination was based on the reaction between $\mathrm{H}_{2} \mathrm{O}_{2}$ and the vanadate anion $\left(\mathrm{VO}_{3}{ }^{-}\right)$in an acid medium to produce peroxivanadium cation $\left(\mathrm{VO}_{2}{ }^{3+}\right)$ as in equation 7, which has an absorption peak at $450 \mathrm{~nm} .{ }^{18}$

$\mathrm{VO}_{3 \text { (aq) }}^{-{ }^{-}}+4 \mathrm{H}_{3} \mathrm{O}^{+}{ }_{\text {(aq) }}+\mathrm{H}_{2} \mathrm{O}_{2(1)} \rightarrow \mathrm{VO}_{2}{ }^{3+}{ }_{\text {(aq) }}+7 \mathrm{H}_{2} \mathrm{O}_{(\mathrm{l})}$

The concentrations of the reagents were used in the optimized range, according to Nogueira et al. ${ }^{18}$ A 9 M sulfuric acid solution $\left(\mathrm{H}_{2} \mathrm{SO}_{4}\right.$, Sigma-Aldrich, $\left.99.99 \%\right)$ was employed to acidify the medium, and ammonium metavanadate $\left(\mathrm{NH}_{4} \mathrm{VO}_{3}\right.$, Sigma-Aldrich, $\left.99.0 \%\right)$ as a source of $\mathrm{VO}_{3}{ }^{-}$ions. These reagents were mixed under magnetic stirring at $50^{\circ} \mathrm{C}$ until complete dissolution, and then diluted to the appropriate concentration. ${ }^{18}$

For the stable reactive nitrogen species characterization, nitric acid $\left(\mathrm{HNO}_{3}\right.$, Sigma-Aldrich, $\left.70 \%\right)$ solutions were prepared through dissolution of the concentrated acid. Nitrous acid $\left(\mathrm{HNO}_{2}\right)$ solutions were prepared with an equimolar mixture of sodium nitrite $\left(\mathrm{NaNO}_{2}\right.$, Synth, $\left.97.0 \%\right)$ and hydrochloric acid ( $\mathrm{HCl}$, Synth, 37.0\%). Both the sampled solutions and the nitric and nitrous acid solutions were directly measured by UV-Vis spectrophotometry.

A UV-Vis spectrophotometer (Thermo Scientific, Genesys 10S) was used to scan the aqueous samples and standard curves from 200 to $800 \mathrm{~nm}$, employing quartz micro cuvettes in all analyses.

\section{Ozone}

$\mathrm{O}_{3}$ produced in the gas phase of the reactor was identified by the Schoenbein paper. It consists of a filter paper dipped in a potassium iodide (KI) and starch solution. When ozone is present, it oxidizes iodide ions to iodine $\left(\mathrm{I}_{2}\right)$, turning the paper color to purple. ${ }^{19}$ At the last sampling time (180 $\mathrm{min}$ ), the prepared Schoenbein paper was placed above the hole of the upper lid to be in contact with the gas phase of the reactor, thus enabling ozone identification.

\section{Conductivity and $\mathrm{pH}$}

Both solution conductivity and $\mathrm{pH}$ were measured at the beginning $(t=0)$ and at the end of the degradations $(\mathrm{t}=180 \mathrm{~min})$ using pre-calibrated instruments.

\section{Results and Discussion}

\section{Kinetic study of $P Q$ degradation}

\section{Temperature effect}

PQ degradation followed a pseudo-second order reaction kinetics, under all experimental conditions. When using the graphical method for determining the order of reaction, the plot of the inverse of PQ concentration gave the best linear fit, with the highest coefficients of determination $\left(R^{2} \geq 0.98\right)$ when compared to both zero $\left(\mathrm{R}^{2}<0.95\right)$ and first order $\left(\mathrm{R}^{2}<0.98\right)$ kinetics. Figure 3 shows a linear correlation between time and the inverse of absorbance, typical of second order kinetics, using $[\mathrm{PQ}]_{0}=10 \mu \mathrm{M}$ and $\mathrm{T}=45.0^{\circ} \mathrm{C}$. In general, most degradations of organic species by plasma follow pseudo-first order kinetics, ${ }^{8-15}$ although pseudosecond order kinetics are also found, as the degradation of amoxicillin in alkaline solution by pulsed corona discharge. ${ }^{16}$

Table 2 shows the effect of temperature on observed rate constant and the removal efficiency. It can be noticed that

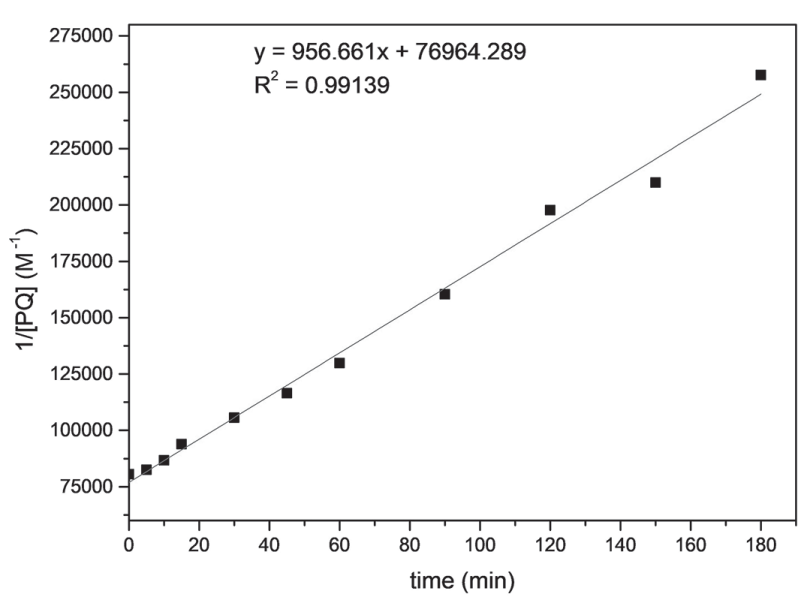

Figure 3. Second-order reaction kinetics for $\mathrm{PQ}$ degradation under surface air discharge $\left(\mathrm{k}_{\mathrm{obs}}=956.66 \mathrm{M}^{-1} \mathrm{~min}^{-1}, \mathrm{~T}=45.0^{\circ} \mathrm{C}\right)$. 
both $\mathrm{k}_{\mathrm{obs}}$ and $\mathrm{RE}$ increased with increasing temperature. The explanation for this is found in the Boltzmann distribution law because it governs the population of states of unequal energy. The activated complex (transition state) represents a high energy state populated according to a Boltzmann distribution. ${ }^{20}$ Thus, it is found from this distribution law that increasing the temperature also increases the population with high energy that is capable to achieve the height of the energy barrier (activation energy), over which the reactants must pass on the way to becoming products. In short, by rising the temperature the Boltzmann distribution reaches higher energies, more molecules are prompted to states of higher energy, and are able to undergo change (chemical reaction). ${ }^{21} \mathrm{RE}$ and $\mathrm{k}_{\mathrm{obs}}$ are directly related; the greater the $\mathrm{k}_{\mathrm{obs}}$ (and thus the rate), the higher the RE at the last sampling time (180 $\mathrm{min})$.

Table 2. Effect of temperature on $\mathrm{k}_{\mathrm{obs}}$ and removal efficiency $\left([\mathrm{PQ}]_{0}=10 \mu \mathrm{M}\right)$

\begin{tabular}{lcc}
\hline Temperature $/{ }^{\circ} \mathrm{C}$ & $\mathrm{k}_{\mathrm{obs}} /\left(\mathrm{M}^{-1} \mathrm{~min}^{-1}\right)$ & $\mathrm{RE} / \%$ \\
\hline 5 & 483.11 & 52.7 \\
15 & 614.32 & 65.0 \\
25 & 699.24 & 65.9 \\
35 & 841.94 & 66.7 \\
45 & 956.66 & 70.7 \\
\hline
\end{tabular}

$\mathrm{k}_{\mathrm{obs}}$ : observed rate constant; RE: removal efficiency.

The Arrhenius plot is shown in Figure 4. The data showed a linear dependence and the calculated activation energy $\left(E_{a}\right)$ for the plasma-chemical degradation was $12.40 \mathrm{~kJ} \mathrm{~mol}^{-1}$.

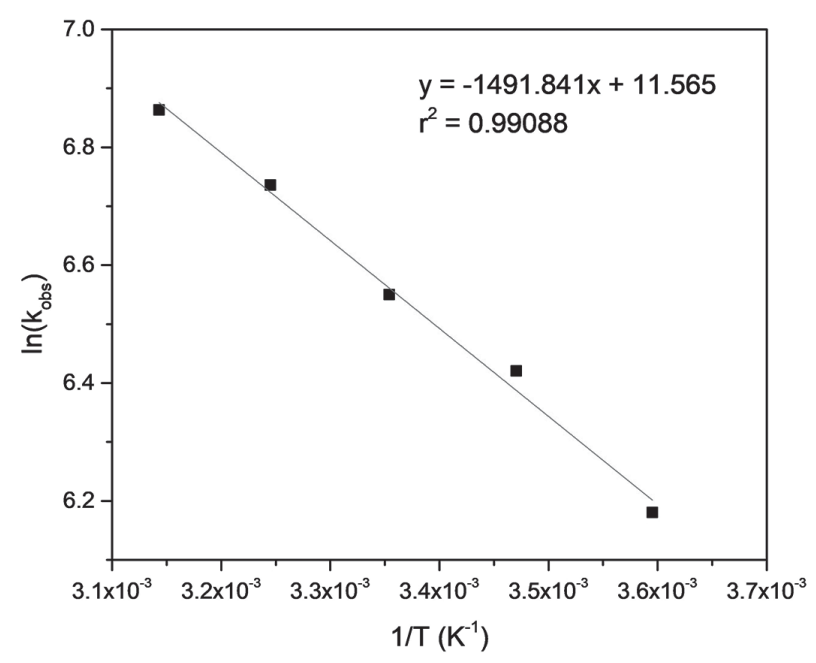

Figure 4. Arrhenius plot for PQ degradation from 5.0 to $45.0^{\circ} \mathrm{C}$.

PQ degradation pre-exponential factor was $105873.5 \mathrm{M}^{-1} \mathrm{~min}^{-1}$. Since PQ is very soluble in water, it is expected to be totally dissociated in solution, producing
$\mathrm{PQ}^{2+}$ and $\mathrm{Cl}^{-}$ions; thus, reactions between ions are predicted. The pre-exponential factor for ionic reactions depends in a rather simple way on the ionic charges. According to the kinetic theory of collisions, if the ions are of opposite signs, the frequency of collisions is increased by the attractive forces, while if they are of the same sign the frequency of collisions is reduced. ${ }^{22}$

The values of both entropy and enthalpy of activation were extracted from the Eyring plot (Figure 5). The calculated entropy of activation was $-157.1 \mathrm{~J} \mathrm{~K}^{-1} \mathrm{~mol}^{-1}$. If the reaction step is bimolecular with two species forming an activated complex resembling a single species, a decrease of entropy of activation is expected, and there is an associative reaction in solution. ${ }^{23}$ In addition, the small enthalpy of activation value, $+9.9 \mathrm{~kJ} \mathrm{~mol}^{-1}$, also supports a bimolecular reaction, since there is bond formation taking place in an associative mechanism..$^{23}$ On the other hand, a higher $\Delta \mathrm{H}^{\ddagger}$ and an increase in $\Delta \mathrm{S}^{\ddagger}$ is expected in a dissociative reaction, as a result of bond breaking and the production of more species in solution, respectively.

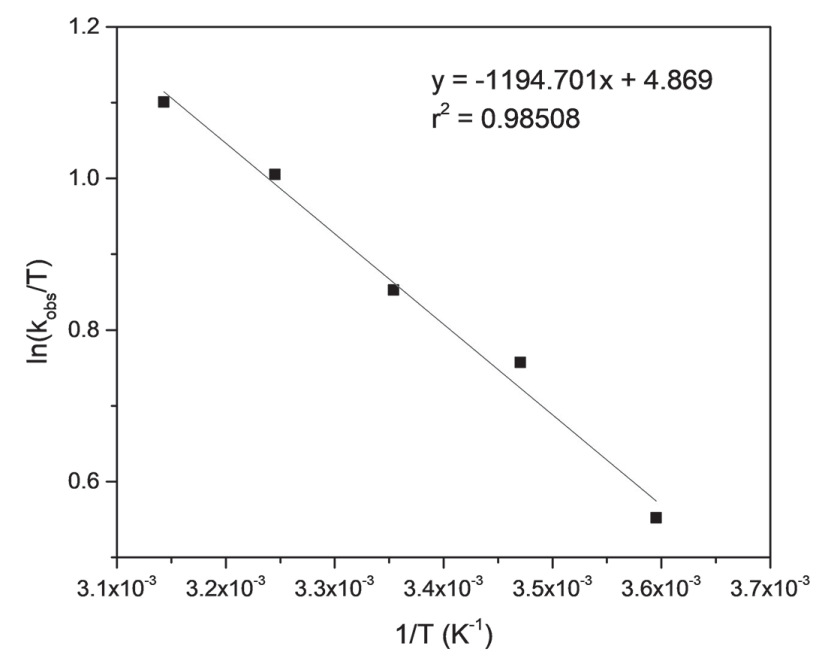

Figure 5. Eyring plot for $\mathrm{PQ}$ degradation from 5.0 to $45.0^{\circ} \mathrm{C}$.

lonic strength effect

Figure 6 shows the dependence between $\log \left(\mathrm{k}_{\mathrm{obs}}\right)$ and the square root of the ionic strength. It can be noticed that the $\mathrm{k}_{\text {obs }}$ values decrease linearly as the square root of the ionic strength increases. This means that the activation complex is formed between 2 ions of opposite charges, as the negative slope $\left(\mathrm{z}_{\mathrm{A}} \mathrm{z}_{\mathrm{B}}\right)$ in equation 5 indicates. The explanation for the decrease on $\mathrm{k}_{\mathrm{obs}}$ with the ionic strength is due to the fact that when the reacting ions have opposite charges, increasing the concentration of ions in the solvent causes a decrease in the attraction between ions, so the rate of the reaction between them is decreased. ${ }^{20}$

The value of the product of the ionic charges $\left(\mathrm{z}_{\mathrm{A}} \mathrm{Z}_{\mathrm{B}}\right)$ is -3.6 , which was obtained from the graph slope. Although 


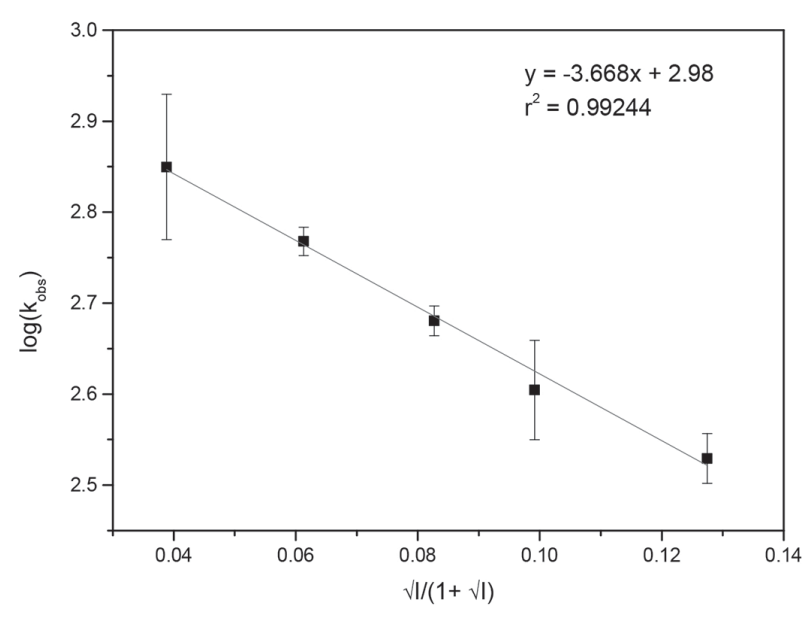

Figure 6. Effect of the ionic strength on $\mathrm{k}_{\mathrm{obs}}$ at $45.0^{\circ} \mathrm{C}$.

the value of the $\mathrm{z}_{\mathrm{A}} \mathrm{z}_{\mathrm{B}}$ product is not exactly -4 , it was possible to conclude that the reaction for producing the activated complex is definitely between 2 ions of opposite charges, since the experiments were repeated 3 times and $\mathrm{k}_{\mathrm{obs}}$ consistently decreased with the increase of the ionic strength. Since $\mathrm{PQ}^{2+}$ already has a +2 charge, it is possible to conclude that the other reacting ions have a -2 charge. Deviations of the integer values are believed to be due to the non-ideal interactions between ionic species in the solution. These deviations from the predicted behavior are common even when the solutions are quite dilute, and it is worth noting that ion pairing and complex formation can cause a relationship to be far from exact. ${ }^{20}$

These observations support that the transition state is formed through the following process:

$\mathrm{PQ}_{(\mathrm{aq})}^{2+}+\mathrm{X}_{(\mathrm{aq})}^{2-} \stackrel{\mathrm{k}_{\mathrm{c}}}{\rightarrow} \mathrm{PQX}_{(\mathrm{aq})} \stackrel{\mathrm{k}_{\mathrm{a}}}{\rightarrow}[\mathrm{TS}]_{(\mathrm{aq})}^{*}$

where $\mathrm{X}^{2-}$ is a divalent anion, which is a reactive species produced by the plasma treatment. In the above scheme, $\mathrm{PQX}_{(\mathrm{aq})}$ is the solvated collision complex of $\mathrm{PQ}^{2+}$ and $\mathrm{X}^{2-}$, while [TS $_{(\text {aq }}^{\ddagger}$ is the solvated transition state. The rate of formation of the collision complex can be characterized by the rate constant $\mathrm{k}_{\mathrm{c}}$ and that of the formation of the transition state by $\mathrm{k}_{\mathrm{a}}$. The rate of diffusion of $\mathrm{PQ}^{2+}$ and $\mathrm{X}^{2-}$ in the solution determines $\mathrm{k}_{\mathrm{c}}$, and there is an activation energy associated with the process. Typically, this activation energy is lower than that required to form a transition state during chemical reaction. As a result, $\mathrm{k}_{\mathrm{c}}>\mathrm{k}_{\mathrm{a}}$, and the formation of the transition state is the rate-determining process. However, in the case of very viscous solvents and strong solvation of reactants $\mathrm{PQ}^{2+}$ and $\mathrm{X}^{2-}$, the formation of the collision complex may be the rate-determining factor. In this case, the rate of the reaction is limited by the rate of formation of the collision complex, and the reaction is diffusion-controlled. ${ }^{20,24}$ Although the activation energy found in this work $\left(12.40 \mathrm{~kJ} \mathrm{~mol}^{-1}\right)$ fits in the range of diffusion-controlled reactions in water, at ordinary temperatures $\left(\mathrm{E}_{\mathrm{a}} \mathrm{ca} .11-15 \mathrm{~kJ} \mathrm{~mol}^{-1}\right){ }^{22,25}$ further investigation will be addressed to compare these results with stirring, and then determine the role of diffusion in the formation of the TS.

\section{$P Q$ concentration effect}

Table 3 shows the effect of the $[\mathrm{PQ}]_{0}$ on $\mathrm{k}_{\mathrm{obs}}$ and RE. As $[\mathrm{PQ}]_{0}$ increased, both $\mathrm{k}_{\mathrm{obs}}$ and $\mathrm{RE}$ decreased for all initial concentrations. Using $10 \mu \mathrm{M}$ of PQ solution, $\mathrm{k}_{\mathrm{obs}}$ increased by a factor of 7 compared to using $50 \mu \mathrm{M}$ of PQ solution. This can be explained by the fact that the same amount of reactive species is generated by the plasma at the same operational conditions. ${ }^{26}$ When $[\mathrm{PQ}]_{0}$ is increased, the limited quantity of reactive species generated at a fixed discharge power reaches its threshold for degradation of $\mathrm{PQ}$, thus leading to a decrease in the degradation rate, ${ }^{27}$ as it can be observed from Table 3 .

Table 3. Effect of $[\mathrm{PQ}]_{0}$ on $\mathrm{k}_{\mathrm{obs}}$ and removal efficiency $\left(\mathrm{T}=25.0^{\circ} \mathrm{C}\right)$

\begin{tabular}{lcc}
\hline$[\mathrm{PQ}]_{0} / \mu \mathrm{M}$ & $\mathrm{k}_{\mathrm{obs}} /\left(\mathrm{M}^{-1} \mathrm{~min}^{-1}\right)$ & $\mathrm{RE} / \%$ \\
\hline 10 & 699.24 & 65.9 \\
15 & 284.13 & 64.0 \\
30 & 197.44 & 63.1 \\
50 & 100.65 & 50.6 \\
\hline
\end{tabular}

$[\mathrm{PQ}]_{0}$ : initial paraquat concentration; $\mathrm{k}_{\mathrm{obs}}$ : observed rate constant; $\mathrm{RE}$ : removal efficiency.

Characterization and chemical kinetics of reactive nitrogen species

In order to check if the stable RNS in the liquid phase were degradation by-products or if they were produced by the air discharge, experiments were done using both ultrapure water and PQ solution.

Figure $7 \mathrm{a}$ shows the UV spectra of ultrapure water submitted to the air discharge at $25{ }^{\circ} \mathrm{C}$. It clearly demonstrates that the surface air plasma-treated water has the characteristic nitric acid absorption peak at $302 \mathrm{~nm}$ and the nitrous acid absorption peaks at 336, 346, 359, 372 and $386 \mathrm{~nm}$. The intensities of these peaks increased with increasing plasma treatment time. Figure $7 \mathrm{~b}$ shows the UV spectra of a $10 \mu \mathrm{M}$ PQ solution submitted to the air discharge at the same temperature. The main difference between Figures $7 \mathrm{a}$ and $7 \mathrm{~b}$, is that Figure $7 \mathrm{~b}$ has a peak at $259 \mathrm{~nm}$, attributed to pure $\mathrm{PQ}$ in solution. Because of $\mathrm{HNO}_{3}$ absorption in the same spectral region, the colorimetric method was employed to determine PQ. Moreover, $\mathrm{HNO}_{3}$ and $\mathrm{HNO}_{2}$ are produced in both media. 
(a)
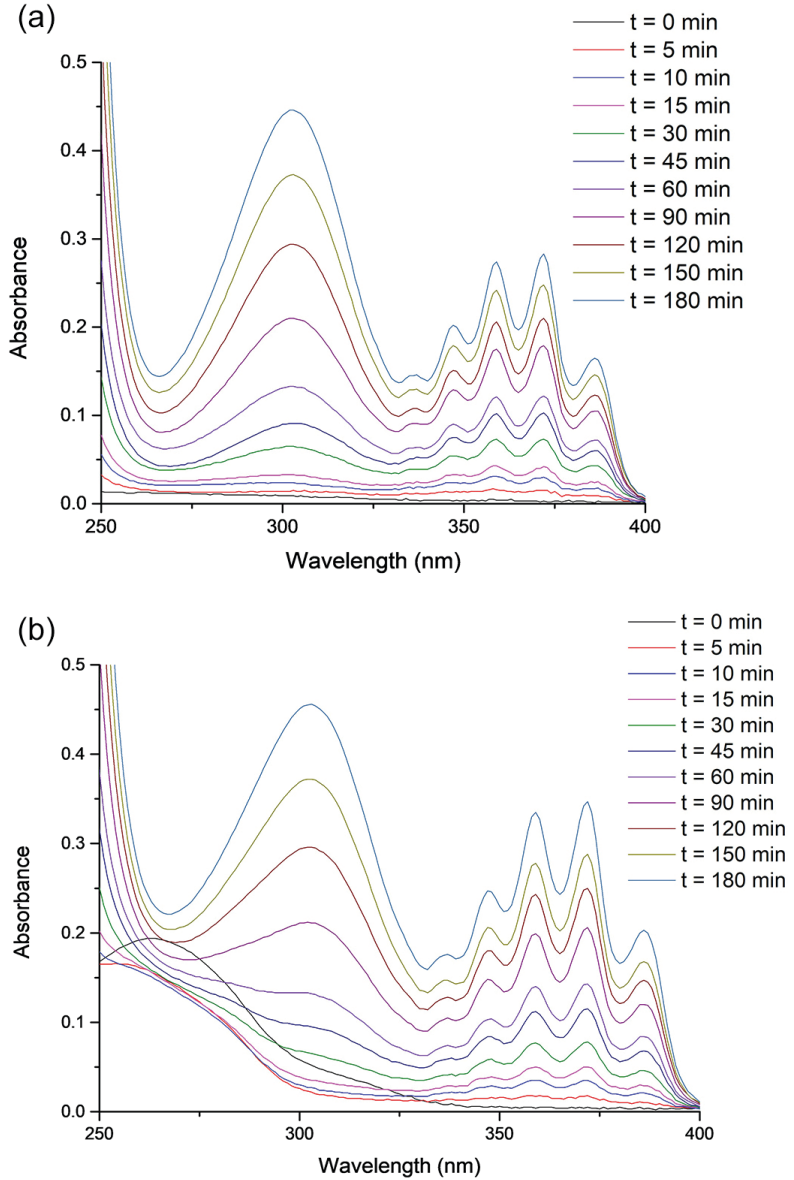

Figure 7. Production of RNS (nitric and nitrous acid) in (a) ultrapure water and (b) $10 \mu \mathrm{M}$ PQ solution during surface air discharge, increasing RNS concentration over time $\left(\mathrm{T}=25.0^{\circ} \mathrm{C}\right)$.

The identity of the produced species was confirmed by comparison of the experimental spectra with those obtained with different $\mathrm{HNO}_{2(\mathrm{aq})}$ and $\mathrm{HNO}_{3(\mathrm{aq})}$ concentrations, separately. The resulting UV absorption peaks match exactly the same wavelengths as those shown in Figure 7.

The chemical kinetics of the nitric and nitrous acids produced under surface air plasma discharge was investigated. In ultrapure water (Figure 8a), the production followed a zero-order kinetic behavior for both species, in accordance with the results found by Lukes et al. ${ }^{15}$ The obtained $\mathrm{k}_{\mathrm{obs}}$ was $2.5 \times 10^{-3} \mathrm{M} \mathrm{min}^{-1}$ for $\mathrm{HNO}_{3(\mathrm{aq})}$ and $1.6 \times 10^{-3} \mathrm{M} \mathrm{min}^{-1}$ for $\mathrm{HNO}_{2(\text { aq }}$, at $25{ }^{\circ} \mathrm{C}$, as shown in Figure 8. At the very beginning of the reaction (until $\mathrm{t}=10 \mathrm{~min}$ ), the data are not linear due to the inducing lag. After 10 min, the relation between absorbance and time is then linear. Since $\mathrm{HNO}_{3(\text { aq })}$ and $\mathrm{HNO}_{2(\text { (aq) }}$ production rates are constant (zero-order), it indicates a direct effect of the surface air plasma. ${ }^{15}$

Figure 8b shows the kinetics for production of $\mathrm{HNO}_{3}$ and $\mathrm{HNO}_{2}$ in a $10 \mu \mathrm{M}$ PQ solution. The production of $\mathrm{HNO}_{3}$ kept its zero-order kinetics with the same value for
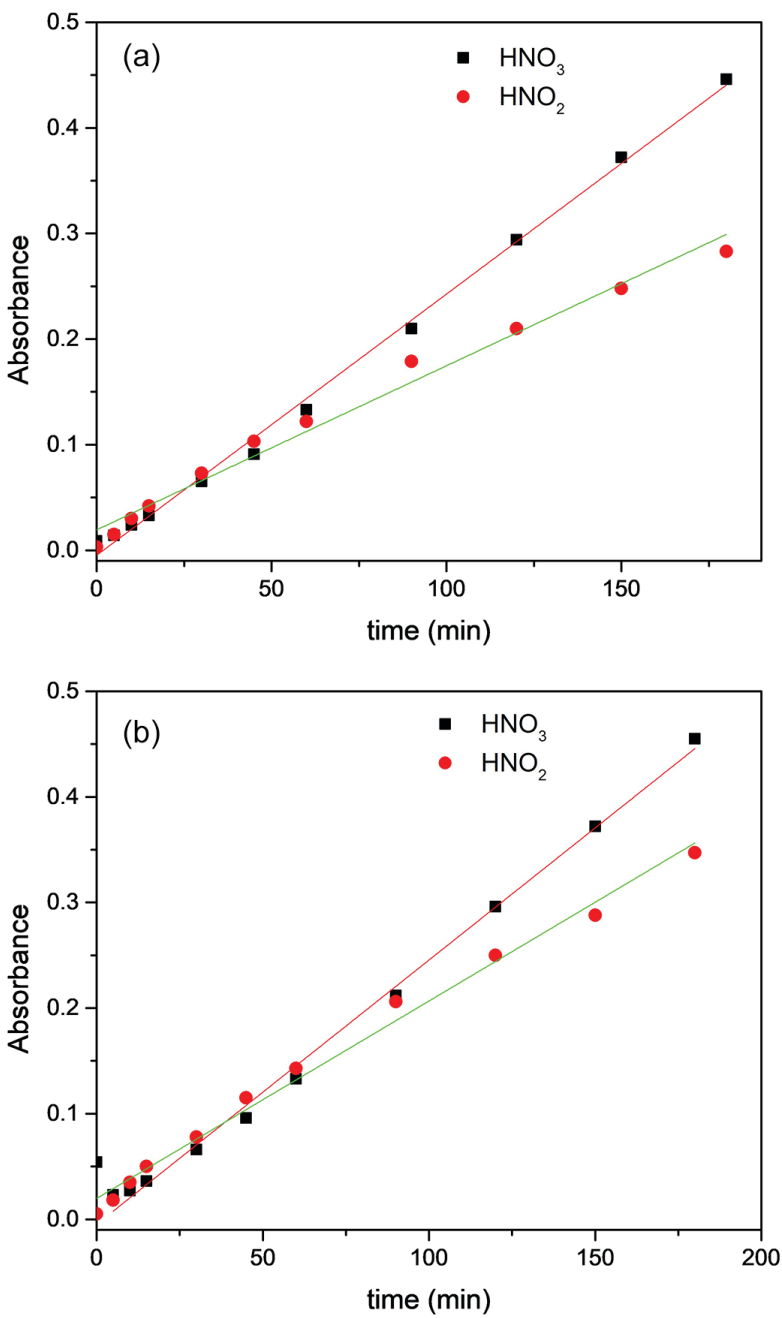

Figure 8. Zero-order reaction kinetics for production of $\mathrm{RNS}\left(\mathrm{HNO}_{3(\mathrm{aq})}\right.$ and $\mathrm{HNO}_{2 \text { (aq) }}$ ) in (a) ultrapure water and (b) $10 \mu \mathrm{M}$ PQ solution under surface air discharge $\left(\mathrm{T}=25.0^{\circ} \mathrm{C}\right)$.

$\mathrm{k}_{\mathrm{obs}}$ in ultrapure water $\left(2.5 \times 10^{-3} \mathrm{M} \mathrm{min}^{-1}\right)$, indicating an analogous behavior for its production in both media. $\mathrm{HNO}_{2}$ production kept following zero-order kinetics, with a little increase on its $\mathrm{k}_{\mathrm{obs}}\left(1.9 \times 10^{-3} \mathrm{M} \mathrm{min}^{-1}\right)$.

For the slope $\left(\mathrm{k}_{\mathrm{obs}}\right)$ calculation, the first data point $(\mathrm{t}=0)$ was not included, because of the strong PQ absorption at $302 \mathrm{~nm}$ (Figures $7 \mathrm{~b}$ and 8b).

As a result of nitric and nitrous acids production, as well as the degradation of the PQ molecule, the $\mathrm{pH}$ of the solution decreased, whereas the conductivity of the solution increased, under all degradations, as shown in Table 4.

\section{Pathways of reactive oxygen species and reactive nitrogen} species

The interaction between a surface air discharge and ultrapure water was studied by both modelling and experimental measurements by Liu et al. ${ }^{28,29}$ The results 
Table 4. Conductivity and $\mathrm{pH}$ of the treated solutions $\left([\mathrm{PQ}]_{0}=10 \mu \mathrm{M}, \mathrm{T}=45.0^{\circ} \mathrm{C}\right)$

\begin{tabular}{lcccc}
\hline Ionic strength / M & $\mathrm{pH}_{0}$ & $\mathrm{pH}_{\mathrm{f}}$ & Conductivity $_{0} /\left(\mu \mathrm{S} \mathrm{cm}^{-1}\right)$ & Conductivity $_{\mathrm{f}} /\left(\mathrm{mS} \mathrm{cm}^{-1}\right)$ \\
\hline 0.00163 & 7.96 & 1.58 & 181.30 & 14.04 \\
0.00426 & 7.90 & 1.55 & 257.50 & 14.95 \\
0.00813 & 7.85 & 1.52 & 432.10 & 15.25 \\
0.01212 & 7.80 & 1.45 & 611.90 & 15.30 \\
0.21330 & 7.76 & 1.30 & 883.50 & 15.45 \\
\hline
\end{tabular}

Conductivity $_{0}$ and conductivity: initial and final conductivity, respectively.

demonstrated that the long-lived aqueous species generated by the plasma were $\mathrm{H}_{3} \mathrm{O}^{+}{ }_{\text {(aq) }}, \mathrm{NO}_{3}^{-}$(aq), $\mathrm{NO}_{2}^{-}{ }_{\text {(aq) }}, \mathrm{H}_{2} \mathrm{O}_{2 \text { (aq) }}$ and $\mathrm{O}_{3(\mathrm{aq})}$. In addition, various short-lived ROS and RNS were also induced in water, regardless whether these species were supplied from the gas phase. It was concluded that the production of aqueous reactive species is controlled by heterogeneous mass transfer and/or chemical reactions in the liquid phase.

The formation of nitric and nitrous acids in the liquid phase and the subsequent $\mathrm{pH}$ decrease was also reported by other researchers using corona discharge or dielectric barrier discharge (DBD) generated above a water surface under air atmosphere. ${ }^{15,28-31}$ Gas-phase reactions in the air plasma produce nitrogen monoxide $\left(\mathrm{NO}_{(\mathrm{g})}\right)$ from dissociated $\mathrm{N}_{2(\mathrm{~g})}$ and $\mathrm{O}_{2(\mathrm{~g})}$; then, $\mathrm{NO}_{(\mathrm{g})}$ is oxidized by $\mathrm{O}_{2(\mathrm{~g})}$ (equation 9) or $\mathrm{O}_{3(\mathrm{~g})}$ (equation 10), generating nitrogen dioxide $\left(\mathrm{NO}_{2(\mathrm{~g})}\right)$ :

$2 \mathrm{NO}_{(\mathrm{g})}+\mathrm{O}_{2(\mathrm{~g})} \rightarrow 2 \mathrm{NO}_{2(\mathrm{~g})}$

$\mathrm{NO}_{(\mathrm{g})}+\mathrm{O}_{3(\mathrm{~g})} \rightarrow \mathrm{NO}_{2(\mathrm{~g})}+\mathrm{O}_{2(\mathrm{~g})}$

Next, $\mathrm{NO}_{2(\mathrm{~g})}$ dissolves in water (equation 11), producing nitrous $\left(\mathrm{HNO}_{2 \text { (aq) }}\right)$ and nitric acids $\left(\mathrm{HNO}_{3(\mathrm{aq})}\right)$ via an electron capture by $\mathrm{NO}_{(\mathrm{aq})}$, as shown in equations 12 and 13:

$\mathrm{NO}_{2(\mathrm{~g})} \rightarrow \mathrm{NO}_{2 \text { (aq) }}$

$2 \mathrm{NO}_{2 \text { (aq) }}+\mathrm{H}_{2} \mathrm{O}_{\text {(l) }} \rightarrow \mathrm{HNO}_{2 \text { (aq) }}+\mathrm{HNO}_{3 \text { (aq) }}$

$\mathrm{NO}_{(\text {aq) }}+\mathrm{NO}_{2(\mathrm{aq})}+\mathrm{H}_{2} \mathrm{O}_{(\mathrm{l})} \rightarrow 2 \mathrm{HNO}_{2(\mathrm{aq})}$

The dissolved $\mathrm{HNO}_{2 \text { (aq) }}$ and $\mathrm{HNO}_{3(\mathrm{aq})}$ reach equilibrium

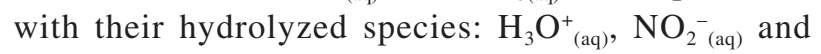
$\mathrm{NO}_{3}^{-}{ }_{\text {(aq) }}{ }^{29}$ therefore reducing the solution $\mathrm{pH}$. As a result, nitrite ions can undergo disproportionation ${ }^{30}$ to nitrogen monoxide and nitric acid, as in equation 14 :

$3 \mathrm{NO}_{2}^{-}{ }_{\text {(aq) }}^{-}+3 \mathrm{H}_{3} \mathrm{O}_{(\text {(aq) }}^{+} \rightarrow 2 \mathrm{NO}_{\text {(aq) }}+\mathrm{HNO}_{3(\mathrm{aq})}+4 \mathrm{H}_{2} \mathrm{O}_{(\mathrm{aq})}($

In the beginning of plasma treatment, when the solution $\mathrm{pH}$ is still approximately neutral, nitrate ions formation may also take place through reaction of $\mathrm{NO}_{2(\text { aq) }}$ with
$\mathrm{OH}^{\bullet}$ radicals to form peroxynitrous acid or its conjugate base peroxynitrite (equation 15). ${ }^{30}$ Then, peroxynitrite isomerizes to nitrate ion, as in equation 16.

$$
\begin{aligned}
& \mathrm{OH}_{(\text {(aq) }}+\mathrm{NO}_{2(\text { aq) }}+\mathrm{H}_{2} \mathrm{O}_{(\mathrm{l})} \rightarrow \mathrm{O}=\mathrm{N}-\mathrm{OOH}_{(\mathrm{aq})}+\mathrm{H}_{2} \mathrm{O}_{(\mathrm{l})} \rightarrow \\
& \mathrm{O}=\mathrm{N}-\mathrm{OO}_{(\mathrm{aq})}^{-}+\mathrm{H}_{3} \mathrm{O}_{(\text {aq) }}^{+} \\
& \mathrm{O}=\mathrm{N}-\mathrm{OO}^{-}{ }_{(\mathrm{aq})} \rightarrow \mathrm{NO}_{3}^{-}{ }_{(\text {aq })}^{-}
\end{aligned}
$$

Ozone was identified in the gas phase of the reactor, by using the Schoenbein paper, which changed its color to purple when exposed to it. Some of the produced ozone may then dissolve on the reactor's aqueous phase and then undergo further reactions. ${ }^{28,29}$ In the presence of ozone, nitrites are oxidized to nitrate and oxygen, thus decreasing nitrite concentration in the solution (equation 17):

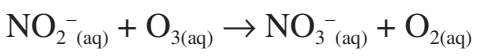

From Liu et al.' ${ }^{28,29}$ modeling and experimental comparison, a large amount of $\mathrm{O}_{3(\mathrm{~g})}, \mathrm{H}_{2} \mathrm{O}_{2(\mathrm{~g})}, \mathrm{N}_{2} \mathrm{O}_{(\mathrm{g})}, \mathrm{N}_{2} \mathrm{O}_{5(\mathrm{~g})}$, $\mathrm{HNO}_{2(\mathrm{~g})}$ and $\mathrm{HNO}_{3(\mathrm{~g})}$ are able to transfer from the gas phase into the aqueous phase in a surface air discharge. However, only $\mathrm{N}_{2} \mathrm{O}_{(\mathrm{g})}$ does not react with other aqueous species. By contrast, $\mathrm{N}_{2} \mathrm{O}_{5(\mathrm{~g})}, \mathrm{HNO}_{2(\mathrm{~g})}$ and $\mathrm{HNO}_{3(\mathrm{~g})}$ greatly react with water to produce $\mathrm{H}_{3} \mathrm{O}^{+}$(aq), $\mathrm{NO}_{2}^{-}$(aq) and $\mathrm{NO}_{3}^{-}$(aq). All of the

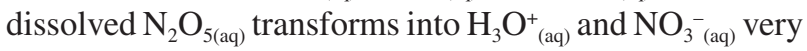
quickly. On the other hand, the dissolved $\mathrm{HNO}_{2(\text { aq })}$ and $\mathrm{HNO}_{3 \text { (aq) }}$ reach equilibrium with their hydrolyzed species $\mathrm{H}_{3} \mathrm{O}^{+}$(aq), $\mathrm{NO}_{2}^{-}$(aq) that aqueous reactive species induced by the surface air plasma were mainly $\mathrm{H}_{3} \mathrm{O}^{+}$(aq), $\mathrm{O}_{3 \text { (aq) }}, \mathrm{H}_{2} \mathrm{O}_{2 \text { (aq) }}, \mathrm{NO}_{3^{-} \text {(aq) }}^{-}$and $\mathrm{NO}_{2}^{-}$(aq).

Although $\mathrm{H}_{2} \mathrm{O}_{2}$ may be produced in the plasma region and in the gas phase of the reactor and then be dissolved in the aqueous phase through mass transfer, ${ }^{28,29}$ $\mathrm{H}_{2} \mathrm{O}_{2 \text { (aq) }}$ quantification by the vanadate method showed that its concentration could not be determined (detection limit $=143 \mu \mathrm{M}$ ). This may be explained by the use of tungsten as the HV electrodes. ${ }^{30-34}$ Tungsten used as HV electrodes has been demonstrated to significantly affect 
the plasma-chemical activity of the discharge in the liquid phase. Reactions of $\mathrm{H}_{2} \mathrm{O}_{2(\mathrm{aq})}$ with solid particles of tungsten and tungstate ions $\left(\mathrm{WO}_{4}{ }^{2-}{ }_{(\mathrm{aq})}\right)$ have been demonstrated through comparison of the yields of $\mathrm{H}_{2} \mathrm{O}_{2(\mathrm{aq})}$ obtained using tungsten electrodes with those determined with other electrode materials (titanium, nickel-chromium, copper, stainless steel, tungsten carbide, and tungsten-copper). ${ }^{33}$ Tungsten-containing electrodes showed lower production of $\mathrm{H}_{2} \mathrm{O}_{2(\mathrm{aq})}$, and a subsequent decrease in the $\mathrm{H}_{2} \mathrm{O}_{2(\mathrm{aq})}$ concentration during the post discharge period (i.e., after discharge being switched off).

In short, the disproportionation of $\mathrm{H}_{2} \mathrm{O}_{2(\mathrm{aq})}$ catalyzed by tungsten ions takes place largely through the production of the mono, di-, and tetraperoxotungstate intermediates, $\left[\mathrm{WO}_{4-\mathrm{n}}\left(\mathrm{O}_{2}\right)_{\mathrm{n}}\right]^{2-}(\mathrm{n}=1,2,4)$, which are transformed again into tungstate ion in acid media, as shown in equations 18 and $19 .^{30}$

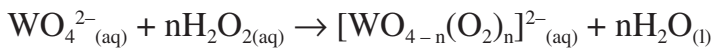

$\left[\mathrm{WO}_{4-\mathrm{n}}\left(\mathrm{O}_{2}\right)_{\mathrm{n}}\right]^{2-}{ }_{(\mathrm{aq})}+2 \mathrm{nH}_{3} \mathrm{O}_{(\text {(aq })}^{+}+2 \mathrm{ne}^{-} \rightarrow \mathrm{WO}_{4}{ }^{2-}{ }_{(\mathrm{aq})}+$ $\mathrm{nH}_{2} \mathrm{O}_{(1)}$

Metallic particles of tungsten that are liberated from the electrodes might also be oxidized by hydrogen peroxide produced by the plasma into $\mathrm{WO}_{4}{ }^{2-}$ (aq) $\left(\right.$ equation 20). ${ }^{30}$

$\mathrm{W}_{(\mathrm{s})}+3 \mathrm{H}_{2} \mathrm{O}_{2(\mathrm{aq})} \rightarrow \mathrm{WO}_{4}{ }^{2-}{ }_{(\mathrm{aq})}+2 \mathrm{H}_{3} \mathrm{O}^{+}{ }_{(\mathrm{aq})}$

Figure 9 shows the UV spectra when there was no addition of a reagent for quenching the solution after sampling, obtained along 7 days. These spectra illustrate typical nitrate and nitrite absorption bands. It can be noticed that nitrite concentration decreased over time, while the concentration of nitrate increased. In an open atmosphere (and thus in the presence of oxygen), nitrite is oxidized to

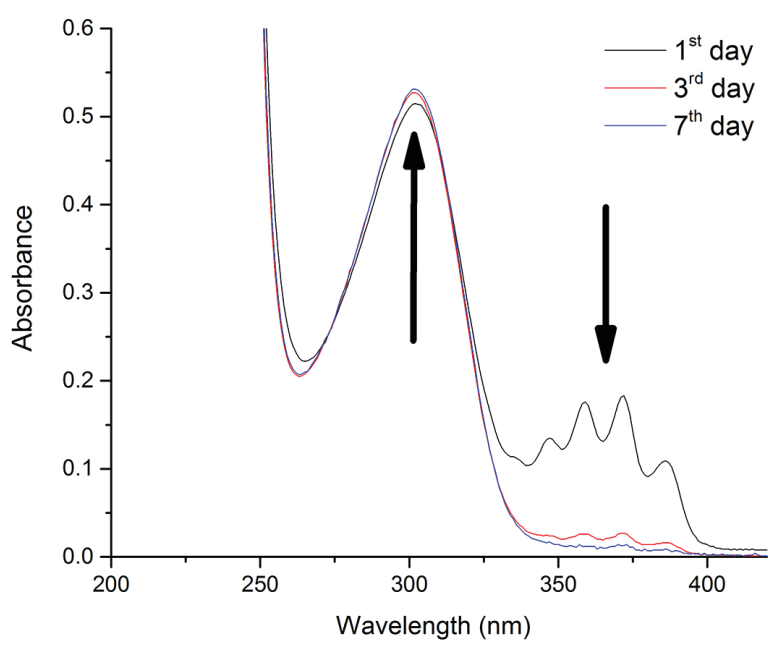

Figure 9. Nitrite oxidation to nitrate after 7 days. nitrate in an acidic medium, as described by the following spontaneous reaction $\left(\Delta \mathrm{G}^{\mathrm{o}}=-111.54 \mathrm{~kJ} \mathrm{~mol}^{-1}\right.$ at $\left.298 \mathrm{~K}\right)$ :

$2 \mathrm{HNO}_{2(\mathrm{aq})}+\mathrm{O}_{2(\mathrm{~g})} \rightarrow 2 \mathrm{H}^{+}{ }_{(\mathrm{aq})}+2 \mathrm{NO}_{3}^{-}{ }_{(\mathrm{aq})}^{-}$

Due to this post-discharge reaction and others that may take place in an acid medium (equation 14), quenching the solution right after sampling with $\mathrm{NaOH}_{(\mathrm{aq})}$ is an essential step for chemical analysis.

\section{Conclusions}

A kinetic study was performed to evaluate PQ degradation mechanism by a surface air plasma system. PQ degradation followed a pseudo-second order reaction kinetics, under all experimental conditions. Both $\mathrm{k}_{\mathrm{obs}}$ and RE increased with increasing temperature, as a consequence of increasing the population with high energy that is capable to achieve the height of the activation energy by increasing the temperature.

Both the decrease of the entropy of activation $\left(-157.1 \mathrm{~J} \mathrm{~K}^{-1} \mathrm{~mol}^{-1}\right)$ and the low value of the enthalpy of activation (+9.9 $\mathrm{kJ} \mathrm{mol}^{-1}$ ) supported a bimolecular associative mechanism for producing the transition state, as two single species are producing one, and there is a bond formation taking place in this case. From the ionic strength effect, it was possible to conclude that the transition state is formed by two ions of opposite charges, with $\mathrm{z}_{\mathrm{A}} \mathrm{z}_{\mathrm{B}}=-3.6$. Therefore, equation 8 was proposed to describe the transition state formation.

The activation energy found in this work $\left(12.40 \mathrm{~kJ} \mathrm{~mol}^{-1}\right)$ supports a diffusion-controlled reaction in water, at ordinary temperatures $\left(\mathrm{E}_{\mathrm{a}}\right.$ ca. 11-15 $\left.\mathrm{kJ} \mathrm{mol}^{-1}\right)$. Because neither gas flow or stirring in the aqueous phase were not used, a diffusion-controlled reaction mechanism is then justifiable and higher rate constants are expected in case of employing any method for solution mixing.

The effect of the $[\mathrm{PQ}]_{0}$ on $\mathrm{k}_{\mathrm{obs}}$ and RE showed that as $[\mathrm{PQ}]_{0}$ increased, both $\mathrm{k}_{\mathrm{obs}}$ and RE decreased for all initial concentrations. This is due to the same amount of reactive species being generated at the same operational conditions, ${ }^{26}$ such as input power, gap distance and temperature. When $[\mathrm{PQ}]_{0}$ is increased, the limited quantity of reactive species generated at a fixed condition reaches its threshold for degradation of PQ, thus leading to a decrease in the degradation rate,${ }^{27}$ analogously to a limiting reagent role in a chemical reaction.

Surface air plasma-treated ultrapure water and PQ solutions produced both nitric acid and nitrous acid. Both production of these species followed zero-order kinetics, in accordance with the literature. ${ }^{15}$ 
After turning off the discharge, liquid phase reactions continued to take place, indicated by the conversion of nitrite into nitrate ions in the acidic medium. Thus, quenching the sampled solution with a basic solution is a crucial step for plasma-treated aqueous phase post analysis.

\section{Supplementary Information}

Supplementary data are available free of charge at http://jbcs.sbq.org.br as PDF file.

\section{Acknowledgments}

The authors would like to thank Dr Philip Martin and Prof Christopher Whitehead (The University of Manchester), and the reviewers, whose comments helped to improve and clarify this manuscript. Thanks also to Prof Keiko Takashima (Universidade Estadual de Londrina) for the discussions and support.

\section{References}

1. Grillo, R.; Pereira, A. E. S.; Nishiasaka, C. S.; de Lima, R.; Oehlke, K.; Greiner, R.; Fraceto, L. F.; J. Hazard. Mater. 2014, $278,163$.

2. Vinhal, J. O.; Lage, M. R.; Carneiro, J. W. M.; Lima, C. F.; Cassela, R. J.; J. Environ. Manage. 2015, 156, 200.

3. Neumeister, L.; Isering, R.; Paraquat: Unacceptable Health Risks for Users, $3^{\text {rd }}$ ed.; Berne Declaration: Zürich; Pesticide Action Network (PAN) UK: London; PAN Asia and Pacific: Penang, 2011.

4. Oliveira, C.; Santos, M. S. F.; Maldonado-Hódar, F. J.; Schaule, G.; Alves, A.; Madeira, L. M.; Chem. Eng. J. 2012, 210, 339.

5. Santos, M. S. F.; Alves, A.; Madeira, L. M.; Chem. Eng. J. 2011, $175,279$.

6. Burrows, H. D.; Canle, M.; Santaballa, J. A.; Steeken, S.; J. Photochem. Photobiol., B 2002, 67, 71.

7. Lee, J.; Kim, M.; Kim, B.; Water Res. 2001, 36, 1776.

8. Dhaouadi, A.; Adhoum, N.; J. Electroanal. Chem. 2009, 637, 33.

9. Dhaouadi, A.; Adhoum, N.; Appl. Catal., B 2010, 97, 227.

10. Sorolla, M. G.; Dalida, M. L.; Khemthong, P.; Grisdanurak, N.; J. Environ. Sci. 2012, 24, 1125.

11. Badli, N. A.; Ali, R.; Bakar, W. A. W. A.; Yuliati, L.; Arabian J. Chem. 2017, 10, 935.

12. Lee, J. C.; Kim, M. S.; Kim, C. K.; Chung, C. H.; Cho, S. M.; Han, G. Y.; Yoon, K. J.; Kim, B. W.; Korean J. Chem. Eng. 2003, $20,862$.

13. Benetoli, L. O.; Cadorin, B. M.; Postiglione, C. S.; Souza, I. G.; Debacher, N. A.; J. Braz. Chem. Soc. 2011, 22, 1669.
14. Magureanu, M.; Bradu, C.; Piroi, D.; Mandace, N. B.; Parvulescu, V.; Plasma Chem. Plasma Process. 2013, 33, 51.

15. Lukes, P.; Dolezalova, E.; Sisrova, I.; Clupek, M.; Plasma Sources Sci. Technol. 2014, 23, 1.

16. Sokolov, A.; Krakstrom, M.; Eklund, P.; Kronberg, L.; LouhiKultanen, M.; Chem. Eng. J. 2018, 334, 673.

17. Infante, M. C.; Rubio-Morales, A.; Guardia, M.; Rocha, F. R. P.; Talanta 2008, 75, 1376.

18. Nogueira, R. F.; Pupo, R. F.; Oliveira, M. C.; Paterlini, W. C.; Talanta 2005, 66, 86.

19. Anfossi, D.; Sandroni, S.; Atmos. Environ. 1997, 31, 3481.

20. House, J. E.; Principles of Chemical Kinetics, $2^{\text {nd }}$ ed.; Elsevier: Amsterdam, 2007.

21. Atkins, P.; Physical Chemistry: A Very Short Introduction; Oxford University Press: Oxford, 2014.

22. Laidler, K. J.; Chemical Kinetics, $3^{\text {rd }}$ ed.; Harper \& Row: New York, 1987.

23. Wright, M. R.; Introduction to Chemical Kinetics; Wiley: Chichester, 2004.

24. Buncel, E.; Stairs, R. A.; Wilson, H.; The Role of the Solvent in Chemical Reactions; Oxford University Press: Oxford, 2003.

25. Rice, S. A.; Bamford, C. H.; Tripper, C. F. H.; Compton, R. G.; Comprehensive Chemical Kinetics, vol. 25; Elsevier: Amsterdam, 1985.

26. Khataee, A.; Gholami, P.; Vahid, B.; J. Ind. Eng. Chem. 2017, $50,86$.

27. Chen, J.; Yulai, D.; Shen, Z.; Lu, S.; Su, K.; Yuan, S.; Hu, Z.; Zhang, A.; Feng, J.; Sep. Purif. Technol. 2017, 179, 135.

28. Liu, Z. C.; Liu, D. X.; Chen, C.; Yang, A. J.; Li, D.; Rong, M. Z.; Chen, H. L.; Kong, M. G.; Sci. Rep. 2016, 6, 1.

29. Liu, Z. C.; Liu, D. X.; Chen, C.; Li, D.; Yang, A. J.; Rong, M. Z.; Chen, H. L.; Kong, M. G.; J. Phys. D: Appl. Phys. 2015, 48, 495201.

30. Luckes, P.; Locke, B. R.; Brisset, J. L. In Plasma Chemistry and Catalysis in Gases and Liquids; Parvulescu, V. I.; Magureanu, M.; Lukes, P., eds.; Wiley-VCH: Weinheim, 2012, ch. 7.

31. Fridman, A.; Fridman, G.; Plasma Medicine; Wiley: Chichester, 2013.

32. Lukes, P.; Clupek, M.; Babickl, V.; Sisrova, I.; Janda, V.; Plasma Sources Sci. Technol. 2011, $20,1$.

33. Holzer, F.; Locke, B. R.; Plasma Chem. Plasma Process. 2008, $28,1$.

34. Brisset, J. L.; Moussa, D.; Doubla, A.; Hnatiuc, E.; Hnatiuc, B.; Youbi, G. K.; Herry, J. M.; Naïtali, M.; Bellon-Fontaine, M. N.; Ind. Eng. Chem. Res. 2008, 47, 5761.

Submitted: December 6, 2017 Published online: March 28, 2018 